\title{
Editorial PIAM June 2021
}

\author{
Eujin Pei ${ }^{1}$
}

Accepted: 28 June 2021 / Published online: 3 July 2021

(c) The Author(s), under exclusive licence to Springer Nature Switzerland AG 2021

Many of us who live and work in Europe would have heard of Horizon Europe, which is the European Union's key funding programme for research and innovation. With a budget of €95.5 billion, the programme aims to facilitate collaboration across member states by generating, developing and disseminating new knowledge and technologies [1]. There are three main pillars of the programme, where Pillar I seeks towards excellence science, Pillar II seeks solutions towards global challenges and European industrial competitiveness, and Pillar III is about initiatives for an innovate Europe. Broadly speaking, most of us working in the field of Additive Manufacturing would be inclined towards Pillar II, Cluster 4 on Digital, Industry and Space that aims to "build a competitive, digital, low-carbon and circular industry, ensure sustainable supply of raw materials, develop advanced materials and provide the basis for advances and innovation in global challenges to society' [2]. Some of the new elements of Horizon Europe include the European Innovation Council that supports high-risk innovations with scale-up potential, having an open science policy, being objective-driven with ambitious partnerships with industry, and 'Missions' that comprise a set of measures to achieve bold, inspirational and measurable goals. Many of the outcomes from these projects from the work programmes may lead to reports and articles being generated and we would be very happy to receive papers that report your work. This could be results from experimental work, capturing the societal benefits, reporting on the economic impact; or you could write about case study reports, produce short communication articles, or a state-ofthe-art review of a particular subject area.

We hope that you will enjoy reading this issue. Have a very good summer.

Eujin Pei

eujin.pei@brunel.ac.uk

Progress in Additive Manufacturing Journal

June 2021

\section{References}

1. https://ec.europa.eu/info/research-and-innovation/funding/fundi ng-opportunities/funding-programmes-and-open-calls/horizoneurope_en. Accessed 20 Jun 2021

2. https://ec.europa.eu/info/research-and-innovation/funding/fundi ng-opportunities/funding-programmes-and-open-calls/horizoneurope/cluster-4-digital-industry-and-space_en. Accessed 20 Jun 2021

Publisher's Note Springer Nature remains neutral with regard to jurisdictional claims in published maps and institutional afliations.
Eujin Pei

eujin.pei@brunel.ac.uk

1 Brunel University London, London, UK 